\title{
Encouraging the Acquisition of Drawing Skills in Game Design: A Case Study
}

\author{
Leila Maani \\ University of Gloucestershire \\ Imaani@glos.ac.uk
}

\author{
Nina Reeves \\ University of Gloucestershire \\ nreeves@glos.ac.uk
}

\begin{abstract}
Undergraduate, interactive, computer games design courses offered by technical universities in the UK, are usually designed to produce graduates who have the knowledge of both the technical and aesthetic aspects of creating interactive computer-based games. These students, unlike students in Art and Design Departments are not required to have art or design backgrounds. However, they need to be able to represent their creative ideas to fellow team members, managers, budget holders and to the audience for the games. Observations by the course team and student module evaluations at the University of Gloucestershire have shown that, although many students have creative ideas about the games that they want to design, they find difficulties in expressing these ideas in a visual manner as they perceive that they do not have adequate drawing skills. Some of these students focus on coding and some eventually get frustrated and withdraw from the course. This paper investigates the links between game design and drawing skills, examining concepts of creativity and education. A longitudinal case study is reported which has identified the problems reported by students and the impact of these on students' attitude and motivation. A variety of tutor-led learning interventions have been trialled. The research has identified criteria to assess the quality of storyboard communications and proposes the design and implementation of an e-learning tool based on game-play to develop storyboarding skills.
\end{abstract}

Computer games design. Drawing. Sketching. Storyboarding. Design communication. E-learning.

\section{INTRODUCTION}

Games have a long history in human culture from ancient times to the present day. They are defined as a problem solving activity approached with a playful attitude (Schell, 2010). The continuing growth of the Internet along with advancing technology related to video games development have fostered more life-like and complex games in terms of graphics and sound effects (Brown, 2008; Gee, 2007) together with different genre possibilities like action games, simulation games, role-playing games, educational games and many others. As a result, video games have become essential aspects of the social lives of many people (Brown, 2008; Gee, 2007; McGonigal, 2010).

It has been suggested that video games are the most advanced form of art thus far in human history because they synthesize text, image, sound, video and the active participation of the audience into a unified, aesthetic experience (Brown, 2008). It has also been suggested that games teach users to think faster, more critically and more creatively. Most agree on one thing: games can influence thinking and actions, and in this sense games can persuade and teach and hence the study of how to create such games has become mainstream in higher education (Brown, 2008; Perry, 2008; Mcgonigal, 2010).

It seems that understanding game design requires an appreciation of a complex web of creativity, psychology, art, technology and business. This subject is now gaining academic credibility with the aim of educating professionals for the game industry. It is therefore important to study how the design skills are acquired and what this will require during the educational process. Although the design of the audio aspects of games is important for the immersive experience (Gärdenfors, 2002; Minkus, 2006), this paper will focus on the visual aspects of Games Design.

Ideas cannot always be expressed easily through text and the visual expression of ideas will in many cases, not only be remembered more easily but also trigger further ideas in the creative process (Corner, 2006). Therefore a game's 'look' in the mind's eye is often very different from the way it looks when it is drawn on paper (Schell, 2010). It is generally believed that creating sketches that are simple, rough and useful as well as being fluent in the language of Graphic Design is a valuable skill that must be practised by a game designer and if not, it is advisable to find an artistic partner so that 
the designer's somewhat nebulous idea may become a concrete vision (Schell, 2010).

This paper reviews the literature of the psychology and taxonomy of drawing (Massironi, 2002) and examines notions of creativity and education (Craft, 2011; Robinson, 2009). It also considers why approaches to design communication may need to change from historical approaches as the requirements of the game design industry develop. Previous solutions to similar interdisciplinary matters in the domain of web design will be reviewed (Ariga and Watanabe, 2008). The paper then describes a longitudinal case study in one university investigating the links between games design and drawing skills. The paper concludes with some suggestions for further work developing interventions to assist students in the development of their storyboarding skills.

\section{REVIEW OF THE LITERATURE}

\subsection{Drawing, seeing and brain functions}

There are different approaches towards drawing in an educational context (Abba, 2007). While some believe that drawing is a natural talent for some people, others believe that drawing and sketching can be taught as a skill (Pariser, 1979; Edwards, 2008; Cheung, 2011; White, 2011). It has also been suggested that the problem reported by students of not being able to draw may be the lack of proper seeing and perception of the object (Nagata, 1999). By drawing, the brain's editing is somehow put on hold, thereby permitting one to see more fully and perhaps more realistically which means that, by drawing, one learns to see (Edwards, 2008; Maslen and Southern, 2011). This has led to Problem Based Learning (PBL) approaches to design education in advertising for instance (Cheung, 2011).

Other studies suggest that human cognitive capacity is divided into two main parts referred to as left brain and right brain (Decosterd, 2008; Edwards, 2008). These argue that the ability to draw may depend on the possibility of accessing the brain's right hemisphere at a conscious level. Some techniques have been developed to help individuals with this access (Bogen, 1975; Edwards, 2008).

Sketching ability can be evaluated by different criteria. A study in the engineering sector has evaluated this ability based on three distinct aspects relevant to engineering design: visual recall, rendering, and novel visualization (Yang and Cham, 2007). Other approaches in the design world have used signifiers based on a semiotic analysis of a task by experienced professional experts (Cheung, 2011).

\subsection{Notions of intelligence and creativity}

'Muscle memory' is a term often used in sports training (Suinn, 2006), but referred to by Robinson (2006) to address the differences between people's sense of being in the world and their ability to function in it. As their whole bodies are engaged in memorising the routines, athletes, musicians, and other performers develop this type of memory which is believed to be beyond the conscious process of thinking. From this viewpoint human intelligence is diverse and not limited to the ability of verbal and mathematical reasoning. It is dynamic, since everyone uses multiple parts of the brain in every task they perform and finally it is distinctive as every person's intelligence is as unique as their fingerprint (Robinson, 2006).

Through imagination people not only bring to mind things that are experienced but things that are never actually experienced (Robinson, 2009). Creativity is the process of imagination which involves processes of generating and evaluating ideas. These processes are very interactive but they don't necessarily come up in a predictable sequence. In this sense creativity is the strongest example of the dynamic nature of intelligence and it can call on all areas of human mind and being (Robinson, 2009).

\subsection{Psychology of learning}

In Miller's pyramid of learning model (Figure 1) the acme of knowledge is being able to do or achieve something, such as, in this case, the ability to communicate ideas in a visual format (Norcini, 2008).

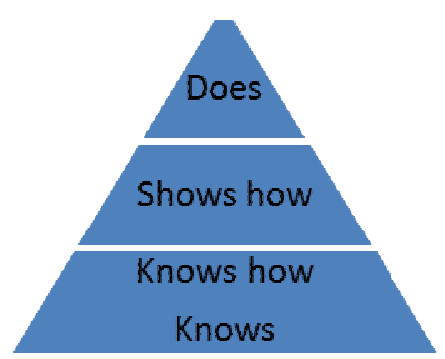

Figure 1: Miller's pyramid of learning

At the core of the psychology of learning is the motivation to learn (Jonassen and Land, 2012). It is argued by several authors that curiosity is a fundamental factor in motivation since curious students are more likely to learn things on their own and more likely to retain what they learnt because they have taken ownership of the material (Murray, 2008; Schell, 2008). However, Smith (2011) suggests that experimental evidence from students 
of architecture indicates that there is no significant relationship between curiosity and academic achievement but that curiosity levels are affected more by active experiences such as travel and relationships. Others have suggested that there is a need to develop new ways to study curiosity, interest and engagement in learning environments which involve more complex uses of media and this paper will suggest that this may include the use of game-play (Arnone, Small, Chauncey and McKenna, 2011).

\subsection{Balancing art and technology}

It seems that the game design industry is the host to some very challenging design problems. There appears to be a need for technical artists within the games design team who have the eye of an artist and the mind of a computer programmer. Industry experts believe that it is such individuals who can build bridges between the art team and the engineering team by being able to speak both of their languages fluently and help to build a product that makes the artists feel in command of the technology and the engineers feel in command of the art (Schell, 2009).

In a different domain, Japanese, non-design students were helped to prepare visualisations of web pages by researchers developing a learning process using worksheets called 'image plots' with standard design templates as teaching materials (Ariga and Watanabe, 2008). The effectiveness of the teaching materials was evaluated by using a questionnaire instrument. Using these worksheets raised students' consciousness of visual expression and gave them a starting point for their designs. This might be thought of as the 'WordPress template' approach to web design but does little to assist the students in expressing their own ideas and in the context of Games Design, the equivalent would be to allow students only to make minor changes to certain aspects of the characters in the game. This would not solve the problem for the students but, by contrast, be frustrating.

Another study focusing on sketching in engineering design considered the role of a designer's sketching ability and examined the potential link between this skill and measures of engineering design performance. The results suggested that sketching skill is not comprehensive nor is it solely task based. Rather, a designer's sketching ability lies between these two poles. This study's findings suggest an important interplay between a designer's ability to sketch and their ability to visualize in their heads or through prototypes. Results also suggested that designers who are given sketch instruction tended to be more willing to express their ideas via drawing (Yang and Cham, 2007). This study clearly emphasises the 'repetition', 'practice' and haptic aspects of sketching skill.

\section{CASE STUDY}

\subsection{The context}

The BSc. Interactive Games Design (IGD) course offered by the School of Computing and Technology of the University of Gloucestershire (UoG) is designed to produce graduates who have the knowledge of both the technical and aesthetic aspects of creating interactive games (UoG, 2010). Students need to represent their creative ideas to fellow team members, managers, budget holders and to the audience for the games. Unlike students in Art and Design Departments, students accepted on this course are not required to have art or design background. Observations by the course team and student module evaluations have shown that although many students have creative ideas about the environments and characters of the games that they want to design, they find difficulty in expressing these in a visual manner as they do not appear to have the drawing skills. Some of these students try to focus on coding and some eventually get frustrated and withdraw from the course citing difficulties with course content. This problem has been a key driver for this study and has been recognised in other institutions where the technical and aesthetic aspects of technology are taught (Ariga and Watanabe, 2008).

The case study set out to follow two groups of students from the start of their course in level 4, establish their base-line storyboarding skills, observe their engagement with a pedagogic intervention addressing these skills and review their storyboarding skills at the end of level 5 . The aim was to develop an understanding of the students' attitudes and motivations with respect to storyboarding in order to develop an e-learning object (JISC, 2009).

\subsection{Methodology}

The methodology of this research is qualitative, emphasizing the authenticity of human experience (Silverman, 2010) with typical features of case study such as data collection via a range of techniques for example observation and interview (Silverman, 2010). Initially the research needed to establish the extent of the problem both from the perspective of the tutors and the institutions and also in the perceptions of the students. This study will be generalizable to an equivalent group of undergraduate students but not to students on a course within an art department as they would have completed an art foundation degree. 
This study is divided into four sub-studies within an Action Research paradigm where the participants are involved in a collaborative process and the research is carried out in an evolutionary manner with the latter parts depending to some extent for their detail on the results of the earlier parts (Coghlan and Brannick, 2005).

Two cohorts, September 2010 and September 2011 intakes, of the IGD course at the University were selected for the case study and were contacted during Induction week to ask permission under the University's Ethical Guidelines for research with human participants. All student work was anonymised during the research.

Initially, it was considered that the educational experience and attitudes to drawing of the students, gained before university, may have some bearing on both their abilities and attitudes. To elicit these baseline attitudes and skills, the students were interviewed at the beginning of their initial module "Introduction to Game Design" and the research process was explained so that they felt involved in the process. Their initial storyboards were also photographed.

The second part of the case study involved observation of students at an art/sketching workshop or pedagogic intervention. Since the first semester has a crucial role in retention (Bousted and May, 2003), the course team arranged a midsemester art workshop providing a set of basic skills for students in order to encourage the development of storyboarding expertise through active learning. This involved a Tutor led workshop where ideas about sketching were explored, simple, mechanical exercises were practised and a more open-ended imaginative task completed in response to a narrative story to mimic the design of a game cut scene. Their storyboard drawings were photographed at the end.

At the end of the "Introduction to Game Design" module, the storyboards which students had designed for their games were collected and reviewed with experts. It was necessary to devise a set of criteria to assess the drawings, so a taster sheet of before and after storyboards was created and a panel of experts, both inside and outside the University commented on the work. This led to the development of a set of criteria by which to assess the drawing communication skills.

For the 2010 cohort, the study has continued into Level 5 where they take a module "Animations for Games" and the storyboards produced for this have been photographed to prepare for further assessment by the panel. The added element here is the use of collaborative group work so the study proposes to investigate the effects that this mode of working has on the attitudes and perceptions of the students. On one hand, it might be thought to be beneficial in that peer encouragement and learning could occur. However, on the other hand, students with less skill might find it discouraging to be working with those with a greater skill level. This part of the research is on-going and will involve qualitative interviews with the 2010 cohort.

\subsection{Results}

\subsubsection{Establishing the extent of the problem}

In the initial stage of the case study, two other Higher Education institutions offering Games courses in Computing Departments were contacted and the tutors interviewed to ascertain whether they experience the same problems as observed at the UoG.

The interdisciplinary nature of the problem was well known to the tutors at both institutions. The response to the problem, however, differed in that at one the students were divided into two groups: Art and Programming. The Art group then had a total of 24 hours of drawing tuition whereas the programming group had no tuition in this aspect. At the other institution, attempts were made to cover storyboarding within modules of the course where it was relevant, such as Animation. There was therefore no evidence of attempts at interventions for all students as at the UoG.

In an attempt to ascertain how the User Interface Design industry views sketching skills, a discussion on the Linkedln User Experience Group was analysed, particularly the thread relating to the question posed, "Hand sketching, does anyone else do it?" (Linkedln User Experience Group Discussion, 2010). The participants' viewpoints were reviewed using Conversation Analysis (CA).

Communication of interface design ideas was regarded as an important aspect of the participants' work. Half the participants start their projects with hand sketching, either with pen and paper or on a whiteboard. For presentations to a larger group, clients or other external audience, $30 \%$ of participants tend to use digital wireframes and mock-ups. In addition to pen and paper, using a whiteboard is favoured by $20 \%$ of participants. In addition, sketch pads and index cards were named. Nearly $38 \%$ of participants use sketching within meetings. Hand sketches are considered to be efficient, easy, fast, flexible, cheap, portable and invaluable to the design process in their reliability. Some suggested that sketching gives feedback that no other media can deliver and in addition helps the design process by making the designer slow down, giving them time to think whilst working, which helps generate new ideas. In some ways, hand sketching has a social nature, making it easy 
to break the ice with peers and customers. It was implied that one doesn't have to be able to draw particularly well to get ideas across to someone. Specific tools and techniques for sketching designs were enumerated: using really thick marker pens for all mock-ups and sketches which allows forms to be drawn at an early stage, but not fine details; evolving designs by scribbling on top of a black and white printout with a red pen when getting feedback and new ideas and finally, using digital mock-ups or scanned sketches, sometimes with digital annotations, so that they can be emailed or put on a projector. The possibility of software tools such as Balsamiq, Axure wire framing and Denim as alternatives to hard copy sketching with pen and paper was also raised.

The requirement for sketching skills from user interface designers in industry, whether of games or other applications, is therefore well recognised and graduates of course such as the IGD BSc will be expected to demonstrate a certain level of skill in this area.

\subsubsection{Student perceptions of storyboarding}

In their first interview at the beginning of the course very few students thought that it would be important and necessary to be able to sketch. The majority believed that having drawing skills would be a bonus and being able to sketch roughly would be enough. Since games design generally involves team work it was thought that there would be some artist in a team who would interpret verbal descriptions. Some said software and technology such as tracing tools in Flash would help them draw. Some believed that the ability to visualize is necessary but not the ability to draw. This suggests that they imagined that they would rely on a concept artist to give life to their ideas.

Some 2010-11 entry students in this study were interviewed again after 3 semesters of study. Most had realized that having storyboarding skills is important in getting ideas across, especially when working in a team. Some believed the need for this skill depends on context of the subject. They found storyboarding necessary to document one's thoughts while working individually and found it to be a more efficient and effective way of developing a concept idea. On the other hand, a few found it waste of time while working individually and preferred to go straight to the authoring software. It seems that most students experienced storyboarding in parallel with the actual design and implementation. They found this approach useful for some situations especially when the limitations of the software were not known to them.

When collating the sketching data with the students' perceptions, it seems that students with natural drawing skills were more confident in drawing on paper to communicate their ideas and felt that it is a more efficient way to communicate. Some were less confident in drawing with software and saw this as a barrier to creativity as it is more time consuming. However, students with a perceived lack of drawing skills often preferred to use rapid prototyping techniques using software tools such as Adobe Flash vector drawing and tracing techniques. The majority of students agreed that the main problem in communicating ideas via drawing is probably due to fear of drawing and lack of confidence. Some believed that they might have the skill, but did not feel confident enough to think that their skill was enough and feared being judged.

A few students said that a person without visual skills or visual awareness is a person who lacks creativity and therefore finds it quite hard to communicate ideas. However, most believed that creativity could not be judged so simplistically and is not necessarily related to drawing skills, citing musicality and the ability to synchronise audio and visuals. A more technical student implied that since technical people are always focused on software limitations for the implementation of ideas, they might limit their creativity so as to improve efficiency in the implementation. The issue of drawing ability was seen by some to be only problematic in individual work since in most team work one could rely on someone else.

Some students said that they appreciated the point of an art workshop but would have preferred more input on this. Some suggested that a module on this issue would be good since they believed that if such a module was able to get the key points across then students wouldn't be so afraid of storyboarding ideas. They thought that learning to storyboard requires more interaction and discussion and therefore software could never replace tutor-led session. Others thought that a software e-learning tool might be helpful, but a more interesting idea was to use such software in conjunction with tutor-led storyboarding sessions, suggesting a blended approach.

Students suggested key requirements for a software e-learning tool would be: where to start with the narrative or characters, time sequence and the way of structuring storyboards, basic drawing techniques and possibly provide readymade icons of objects like vehicles, for dragging and dropping when thinking about aspects of narrative. A multimedia aspect was deemed important too, with short video clips demonstrating key points which could be reviewed more than once. 


\subsubsection{Criteria to assess the storyboards}

In order to develop a baseline assessment of the students' skills in storyboarding, expert views were sought as to appropriate criteria to be used with the students' work. From the perspective of games design, elements necessary for the basic sketching vocabulary may be categorised into objects (still life), people (figure- human form) and landscape sometimes referred to as props (sic), characters and environment in Games Design.

From a Graphic Design perspective, criteria for evaluating drawing skills may involve some or all of the following: effective use of line, positive and negative space, illusion of perspective, indication of depth and distance, revealing form through light and shadow, level of detail, observational skills, texture-energy, composition and balance, proportion, scale, information value, use of colour, drawing style, character proportions, gestures and poses, indication of movement and relationship to background environment. From these, the experts suggested that the most applicable criteria to assess the elements of sketching for storyboards are:

- Effective use of line,

- positive and negative space,

- Illusion of perspective,

- light-shadow,

- Texture- energy.

In addition to these, however there are some elements specific to games storyboarding: time sequence ie: having a beginning, middle and end, communicating information about the location where the interaction takes place, characterization ie: presenting the people as personalities, providing details about the other actions and things characters are doing as they interact, emphasizing actions and emotions by adding visual annotations to the sketches if needed and finally, aspects of user controls.

\subsubsection{Problems identified by the panel}

The panel were provided with the drawings which the students had created as part of the storyboarding workshop undertaken during Semester 1 of their course. When applying the criteria, the Panel of experts noted that students appear to have trouble with analysing their illustration into component elements which means that they struggle to think compositionally as illustrated in Figure 2. This drawing can be set in contrast to Figure 3 where more of the criteria are satisfied eg: good composition, illusion of perspective, light and shadow, communication of location information as well as information about a character's interests and intentions.

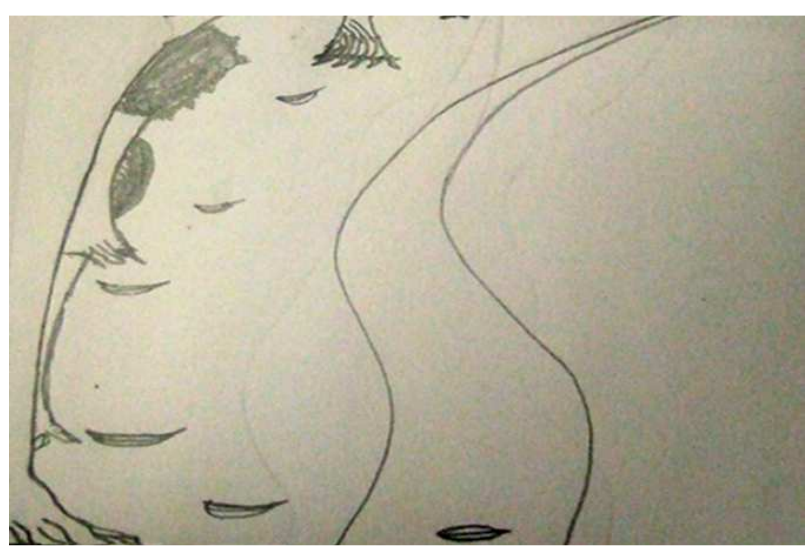

Figure 2: Storyboard sketch 1

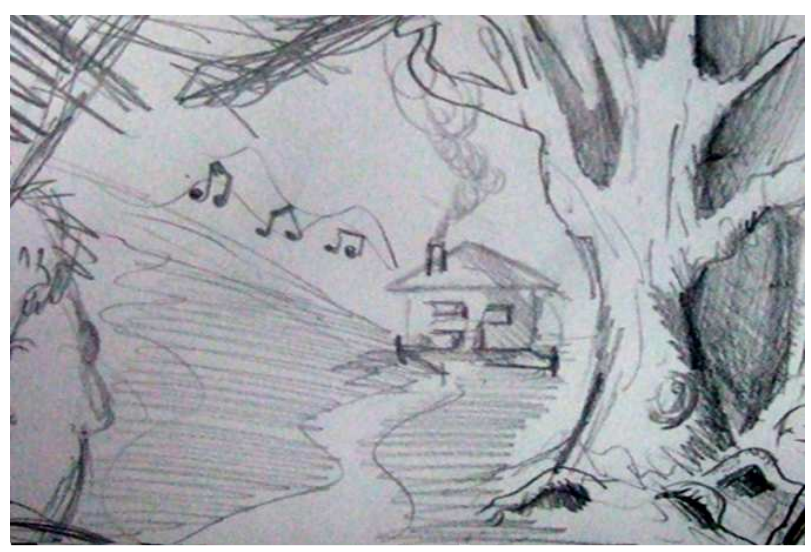

Figure 3: Storyboard sketch 2

\section{CONCLUSIONS AND FURTHER WORK}

\subsection{Holistic approach to solutions for the perceived problem}

The literature review suggested in 2.4 that there is a need for a convergence of thinking between the technical and aesthetic aspects of games design and that there exists a need for designers who can build bridges between the art team and the engineering team by being able to speak both of their languages fluently. Research with the students has suggested that they perceive 'lack of confidence' as a major barrier to being able to express their ideas creatively via sketched storyboards. They are in the main, however, confident with software tools and can envisage an e-learning tool used in a blended learning environment with a tutor to improve their abilities and confidence.

To ensure that the e-learning is not seen in isolation, the design of assessment work has been adjusted to incorporate the use of animatics, so that students who prefer using a software approach to storyboarding may communicate their ideas using a full range of audio and visual media rather 
than simply relying on the media in which they feel least comfortable, namely hard copy sketching.

\subsection{Design of the e-Learning object}

It is proposed to develop a set of learning objects incorporating a range of multimedia to demonstrate basic techniques and allow them to practise these without fear of external judgement. The criteria developed in conjunction with the expert panel (3.3.3) will be used as a basis for the design of the software. Using the students' interest area, this should include gameplay aspects such as puzzle solution, communication of ideas and fun with a social networking aspect to capitalise on their preferred methods of interacting with each other online.

\section{REFERENCES}

Abba, T. (2007) A grammar, form and content for interactive narrative. Ph.D., West of England, 575207 (BL: DXN113002)

Ariga, T. and Watanabe, T. (2008) Teaching Materials to Enhance the Visual Expression of Web Pages for Students not in Art or Design Majors, Computers and Education. 51: 815-828.

Arnone, M.P, Small, R.V, Chauncey, S.A. and McKenna H.P. (2011) Curiosity, Interest and Engagement in Technology-Pervasive Learning Environments: a New Research Agenda. Educational Technology Research and Development. 59(2) pp:181-198.

Atherton, J.S. (2011) Learning and Teaching: Constructivism in Learning. [online available from http://www.learningandteaching.info/learning/constr uctivism.htm Last accessed March 2012]

Bogen, J. E. (1975) Some Educational Aspects of Hemispheric Specialization, UCLA Educator 17: 24-32.

Bousted, M and May, S. (2003) Shall I stay or shall I go: Students who leave Kingston University in semester one SEDA Journal of Educational Developments. 4.2.

Brown, H. J. (2008) Video Games and Education, New York, M.E. Sharpe.

Chueng, M. (2011) Creativity in Advertising Eduvcation: an Experimental Study. Instructional Design: An International Journal of the Learning Sciences. 39(6) pp:843-864.

Coghlan, D. and Brannick, T. (2005) Doing Action Research in your own organization. $2^{\text {nd }}$ ed. London: Sage.

Corner, L. (2006) Code of Practice for the Visual Arts - Artists. a-n The Artists Information Company [online available from http://www.a- n.co.uk/knowledge bank/article/92660 accessed March 2012]

Last

Edwards, B. (2008) The New Drawing on the Right Side of the Brain, London, Harper Collins.

Gärdenfors, D. (2002) Designing sound-based Computer Games. Proceedings of the Cybersonica International Festival of Music and Sound, June 2002. [online available from http://audiogames.net/pics/upload/gardenfors.pdf Last accessed March 2012]

Gee, J. P. (2007) What Video Games Have to Teach Us about Learning and Literacy, New York, $\mathrm{NJ}$ : Palgrave Macmillan.

JISC (2009) Effective practice in a digital age: a guide to technology-enhanced learning and teaching. Bristol: HEFCHE.

Jonassen D. and Land S. (eds) (2012) Theoretical Foundations of Learning Environments. $2^{\text {nd }} \mathrm{ed}$. Oxford: Routledge, Taylor and Francis.

Linkedln User Experience Group (2010) Discussion: 'Hand Sketching, Does Anyone Else Do It?', [online available from http://www.linkedin.com. Last accessed June 2010.]

Madden, M, Chung, P.W.H. and Dawson, C.W. (2009) Cartoons beyond clipart: A computer tool for storyboarding and storywriting. Computers and Education 52(1) pp: 188-200.

Mason, J. (2002) Qualitative Researching, London: Sage.

McGonigal, J. (Feb 2010) Gaming Can Make a Better World. Ted Talks: Ideas Worth Spreading, [online available from http://www.ted.com/talks. Last accessed April 2010.]

Maslen, M and Southern, J (2011) Drawing Projects: An Exploration of the Language of Drawing. (in press) London: Black Dog Publishing.

Minkus, K. (2006) Audio in casual web, downloadable and xbox live arcade games. IGDA Casual Games Quarterly, 2(1) Fall 2006. [online available from http://archives.igda.org/casual/quarterly/2 1/index. php?id=7 Last accessed March 2012]

Murray, A. (2008) Public Perceptions of Montessori Education, [online available from http://www.amshq.org/research/Murray Dissertatio n.pdf. Last accessed Dec 2010.]

Nagata, T. (1999) An investigation into spatial visualisation ability and drawing strategies in the training of designers in a Japanese context. Ph.D., De Montfort, 53-12630 (BL: DXN049969)

Norcini, J. (2008) An introduction to the assessment of skills and performance. Proceedings of AMEE 2008 [online available from 
http://www.amee.org/documents/Introduction\%20to \%20Medical\%20Education\%20-\%20Norcini.pdf Last accessed Dec 2011]

Pariser D.A. (1979) Two methods of teaching drawing skills. Studies in Art Education 20(3) pp3042.

Perry, D. (2008) Video Games. Ted Talks: Ideas Worth Spreading, [online available from http://www.ted.com/talks. Last accessed June 2010]

Robinson, K. (2006) Schools Kill Creativity. Ted Talks: Ideas Worth Spreading, [online available from

http://www.tannerlectures.utah.edu/lectures/docum ents/popper80.pdf. Last accessed Dec 2011]

Robinson, K. (2009) The Element: How Finding Your Passion Changes Everything, London, Penguin Books.

Schell, J. (2008) The Art of Game Design: A Book of Lenses. Burlington: Morgan Kaufmann.
Silverman, D. (2010) Doing Qualitative Research. London: Sage.

Smith K. (2011) Curiositas and Studiositas: Investigating Student Curiosity and the Design Studio. International Journal of Art and Design Education 30(2) pp:161-175.

Suinn R.M. (1997) Mental Practice in Sports Psychology: where have we been, where do we go? Clinical Psychology: Science and Practice 4(3) pp189-207.

University of Gloucestershire (2010) Interactive Games Design 2010 Entry, [online available from http://www.glos.ac.uk Last accessed March 2010]

White K. (2011) 101 Things to Learn in Art School. Cambridge, MA: MIT Press.

Yang, C. and Cham, G. (2007) An Analysis of Sketching Skill and Its Role in Early Stage Engineering Design, ASME. 129: 476-482. 